\title{
GASTRODIPLOMACY INDONESIA DI BELANDA ERA PEMERINTAHAN JOKO WIDODO
}

\author{
Yeremias/ Erna Kurniawati \\ yeremiaas@gmail.com
}

eh Dalam

atice Hall.,

ika Utama.

ion. Person

oran Suara

itatif Dan $R$

The purpose of this research is to identify kind of Indonesian diplomacy through zantomacy in Netherlands under Joko Widodo era. Indonesia 's gastrodiplomacy wnat Altesses to promote the richness of Indonesian culinary, having been done both - zorment and non government actors. They created various occasions which held x net cities in Netherlands. The aim of Indonesia's gastrodiplomacy in Netherlands is a promet the richness culinary of Indonesia, so that, it would be more popular in kestriluds. The other advantage of Indonesia gastrodiplomacy is, people of tenterls would be interested in visiting Indonesia. This research used both gastro alimacy concept and public diplomacy, especially in various Indonesia's culinary, and anuied by using qualitative research methods. Finally, the research indicated those narinctis gastrodiplomacy efforts to the Netherlands, which conducted both by proersment actors and non-government actors, were effective to promote Indonesia mext Indonesia 'a culinary.

G-verds: Gastrodiplomacy, Indonesia, Joko Widodo, Netherlands.

therak

T-juan dari penelitian ini adalah untuk memahami bentuk-bentuk diplomasi = esesia di Belanda melalui gastrodiplomacy era pemerintahan Joko Widodo. Dengan Tnme- lindonesia melalui kulinernya yang sangat beragam dan kaya citarasa, diharapkan marat Belanda akan lebih mengenal Indonesia, dan pada akhimya akan tertarik merkinjung ke Indonesia. Penelitian yang dilakukan dengan menggunakan metode meinan kualitatif ini menunjukkan bahwa upaya gastrodiplomacy Indonesia di Belanda alias sain tidak hanya oleh aktor pemerintah, namun juga oleh aktor non pemerintah, dan maxn saling bersinergi dengan melalui berbagai media.

Lan Kasi: Belanda, Gastrodiplomacy, Indonesia, Joko Widodo.

\section{Matatuluan}

twir-akhir ini, makanan semakin lazim digunakan sebagai sarana untuk diplomasi mans satu negara. Melalui keanekaragaman, cita rasa dan bahkan filosopi kuliner yang menisi kekhasannya, suatu negara dapat memperkenalkan dan mempromosikan mana pada masyarakat negara lainnya. Diplomasi kuliner yang dikenal juga dengan 
gastrodiplomacy ini antara lain seperti sudah lazim dilakukan oleh Jepang dengan diplomasi Washoku, atau Korea Selatan dengan diplomasi Kimchi.

Mengingat Indonesia adalah negara kepulauan dengan berbagai suku, yang kaya akan aneka kuliner, maka gastrodiplomacy sudah semestinya juga menjadi alternatif pilihan menarik untuk dikembangkan. Kelezatan, kekhasan dan keanekaragaman kuliner Indonesia bahkan dapat menjadi daya tarik tersendiri. Kelezatan beberapa masakan di Indonesia sudah terkenal didunia, diantaranya sate, nasi goreng dan rendang. Rendang, masakan pedas berempah dari Sumatera Barat, bahkan pernah dinobatkan sebagai makanan paling lezat berdasar survei CNN tahun 2011. Chef terkenal Australia, George Calombaris bahkan mengakui kemungkinan kuliner Indonesia untuk mendunia. (Your Pick: World's 50 Best Food, http://edition_cnn_com/travel/article/world-best-foods-readers: choice/index.html, diakses 16 November 2017). Namun demikian fakta menunjukkan bahwa masakan Indonesia yang beraneka ragam dan kaya cita rasa tersebut sering kalah populer dibanding masakan tomyam Thailand atau nasi lemak Malaysia, misalnya. Hal ini tampak antara lain di Ceko, dimana meski masakan Indonesia sudah dikenal, namun masih kalah populer dibanding masakan Vietnam dan Thailand. Duta Besar Republik Indonesia untuk Ceko, Aulia Rachman mengakui :"Makanan terpopuler di Praha adalah masakan Vietnam dan Thailand. Bahan baku mereka sudah tersedia di berbagai toko Asia disini dan mudah juga didapatkan, kalau bahan baku masakan Indonesia masih agak sulit. (Eksklusif Dubes RI Untuk Ceko: Di Ceko, Makanan Indonesia Masih Kalah Populer dari Vietnam, https://www_cnnindonesia.com/gaya-hidup/20170515141904-262-214922/ diceko-makanan-indonesia-masih-kalah-populer-dari-vietnam).

Pemerintah Indonesia melihat adanya potensi besar dalam penggunaan gastrodiplomacy sebagai pendekatan soft power untuk memperkenalkan dan meningkatkan diplomasi publik dan citra negara di dunia internasional. Di sisi lain, pemerintah Indonesia menyadari semakin pentingnya pendekatan soft power dalam diplomasi, namun secara spesifik belum menjadikan gastrodiplomacy sebagai fokus utama dari kebijakan strategis pemerintahan Joko Widodo. Kementrian Luar Negeri Indonesia mengutip RENSTRA KEMENLU (Rencana Strategis Kementrian Luar Negeri Indonesia) tahun 2015-2019 halaman 50, dalam Poin $\mathrm{x}$ tercantum "Menggunakan 
ig dengan

kaya akan

atif pilihan

in kuliner

asakan di

Rendang,

in sebagai

ia, George

inia. (Your

ds-readers:

nunjukkan

ering kalah

alnya. Hal

aal, namun

Republik

aha adalah

i toko Asia

agak sulit.

opuler dari

$14922 / \mathrm{di}-$

enggunaan

alkan dan

ii sisi lain,

wer dalam

agai fokus

uar Negeri

uar Negeri

nggunakan

Kama demikian, sebenarnya, setidaknya sejak tahun 2011 Indonesia sudah menemain sustrodiplomacy sebagai soft power, yakni ketika beberapa makanan aman-ma afmbutkan menjadi makanan terlezat di dunia. Sejak saat itu Indonesia dengan Par ne kan berbagai event kuliner di berbagai Negara, dan terlebih di Eropa.

Pumeristah melihat bahwa hal tersebut merupakan suatu kesempatan yang baik me hutmesit untuk mempromosikan negara, agar lebih dikenal. Jika Thailand, Korea Sear: ar lepang bisa mempromosikan negaranya melalui makanan, maka Indonesia ape setarenya dapat bergerak dalam gastrodiplomacy. Berbeda dengan Thailand mare Selatan, gastrodiplomacy Jepang misalnya, dilakukan dengan menertake Washoku sebagai bagian dari budayanya. Washoku merupakan sebuah mark sali berdscarkan seperangkat keterampilan, pengetahuan, praktik, dan tradisi ane enutul dengan produksi, pengolahan, persiapan, dan konsumsi makanan. Hal ini merur setagi suatu penghormatan kepada alam terkait dengan pemanfaatan sumber abre aurn secan berkelanjutan. (UNESCO-ICH 2013, Washoku, traditional dietary cultures

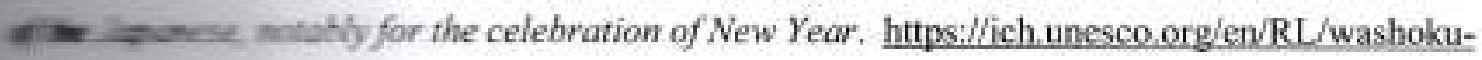

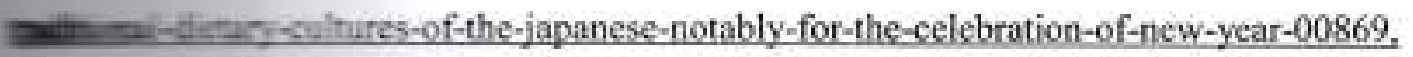

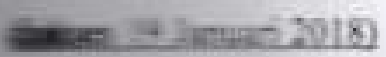

Sarna halnya dengan Korea Selatan, Thailand ataupun Jepang, sebetulnya =me Laine lndonesia yang potensial untuk digunakan sebagai ikon gastrodiplomasi. Reary, nusakan khas berbumbu rempah yang berasal dari Sumatera Barat, misalnya, בu nentabi referensi kuliner papan atas dunia, antara lain tampak dari dinobatkannya Almasy setugi makanan terlezat di dunia versi CNN Travel tahun 2011. Kemudian ave sose kada ada Nasi Goreng, dan Sate pada posisi ke empat belas...Cheung, T. Fond is 50 Bear Foods, http:/travel.cnn.com/explorations/ eat/readers-choice-worldsLans-2esoufoods-012321/) (diakses pada 6 Juni 2017) Selain nasi goreng an sate, Kopi Lav Indoncsia juga termasuk dalam daftar kopi termahal di dunia sejak tahun 
2005. (National Geographic: Sejarah Kopi Luwak, Kopi Termahal di Dimia. (2016). Tersedia dari: http//nationalgeographic.co.id/berita/2016/02/sejarah-kopi-luwak-kepi-termahal-di-dunia). Hal ini tak pelak membuat nama Indonesia sebagai salah satu 'surga aneka kuliner' dunia dengan citarasa luar biasa, makin dikenal.

Selain berbagai makanan di atas, salah satu makanan khas Indonesia yang terbuat dari kacang kedelai, Tempe juga semakin populer di dunia. Di Belanda, tempe (tempeh) relatif mudah didapat karena tersedia di Toko Oriental yang tersebar di berbagai kota besar di Belanda. Di Toko tersebut, tempe setiap hari tersedia dengan harga relatif terjangkau sekitar 1,4 euro, dengan ukuran relatif besar. Di Inggris tempe juga relatif populer. William Mitchell misalnya, bahkan sudah 3 tahun terakhir ini membuka warung tenda di London. Mitchell mengatakan ia langsung jatuh cinta pada tempe, sejak mengenalnya sekitar 10 tahun lalu di Jakarta, dan lalu memutuskan untuk membuka warung tenda tempe. Warung tendanya ini mendapat antusiasme dari masyarakat. (Mengapa Pilih Tempe Untuk Bisnis Kuliner di London? http://www.bbc.com/indonesia/ majalah/2016/09/160923 trensosial_tempe Iondon, diakses 18 Januari 2018.)

Mengapa Pilih Tempe Untuk Bisnis Kuliner di London? http://www. bbc.com/indonesia/majalah/2016/09/160923 trensosial tempe london, diakses 18 Januari 2018. Di kawasan Asia, seperti di Jepang misalnya, berawal dari scbuah bazaar kuliner Jepang, Rustono, warga Indonesia yang bermukim di Jepang, dan saat ini dijuluki sebagai raja tempe, setiap hari memproduksi satu ton tempe per hari, bahkan produknya telah merambah Meksiko dan Korea. Ia mengatakan di Jepang tempe dikenal sebagai 'magic food', bahkan di Meksiko dijuluki sebagai 'heaven food', julukan ini terkait kandungan gizi tempe yang berbahan utama kedelai, apalagi jika dibandingkan dengan junk food. Tempe: 'Makanan Ajaib' yang (Masih) Dianggap Murahan di Indonesia, http://www.bbc.com/indonesia/indonesia-38529395, diakses pada 9 Juni 2017.

Optimisme agar makanan khas Indonesia semakin dikenal dunia, tampak dari upaya Perhimpunan Ahli Gizi dan Pangan (Pergizi Pangan) Indonesia, bersama Forum Tempe Indonesia yang mengajukan Tempe sebagai Warisan Budaya Non Benda (Intangible Cultural Heritage of Humanity )/ ICHH yang diakui UNESCO. (Tempe 
6). Tersedis al-di-dunia). iner" dunia iesia yang nda, tempe di berbagai arga relatif juga relatif uka warung mpe, sejak k membuka masyarakat. n/indonesia/ ) bttp://www, iakses $\quad 18$ buah bazaar t ini dijuluki n produknya enal sebagai in ini terkait gkan dengan ii Indonesia, 17.

tampak dari sama Forum Non Benda CO. (Tempe 
bermukim di Belanda, serta makin banyaknya mahasiswa yang berasal dari Indonesia yang melakukan studi di berbagai kota di Belanda. Untuk membatasi jangkauan penelitian, maka penelitian dibatasi pada era pemerintahan Joko Widodo.

\section{Metode Penelitian}

Penelitian dlakukan dengan metode kualitatif dengan secara umum merujuk pada pengumpulan data dan strategi atau tehnik analisis data, yang bergantung pada data non numerik untuk mendapatkan pemahaman yang lebih baik tentang bagaimana kita memahami dan memaknai dunia sekitar. Dengan merujuk pada tehnik analisis kualitatif Berg dan Lune, penelitian ini dilakukan secara kualitatif, dengan tehnik analisis isi (content analysis). Analisis isi yang dimaksud adalah sebagai aktifitas dimana peneliti meneliti artefak komunikasi sosial, termasuk didalamnya data tekstual, program televisi, foto dan bentuk-bentuk seni lainnya (Umar Suryadi Bakry, Metode Penelitian Hubungan Internasional, 2016:73) . Adapun teknik pengumpulan data dilakukan dengan berupa library research, yaitu teknik pengumpulan data dengan mengumpulkan informasi dari buku-buku, literatur, jurnal, artikel, website, media cetak dan media elektronik yang sesuai dengan masalah dan mengadakan studi terhadap berbagi buku, literatur, jurnal, artikel, karya ilmiah, website baik dalam bentuk media cetak maupun media elektronik, untuk kemudian diolah menjadi data untuk menganalisis. Adapun tujuan penelitian ini untuk memahami bagaimana upaya gastrodiplomacy Indonesia di Belanda era Pemerintahan Presiden Joko Widodo dilakukan. Sedangkan manfaat dari penelitian ini untuk memperkaya wawasan mengenai pentingnya kegiatan promosi dalam hubungan antar negara seperti halnya diplomasi publik. Dalam dunia internasional, diplomasi publik adalah sarana promosi di mana semakin banyak negara mencoba untuk bersaing di panggung global untuk memperkenalkan negaranya bahkan juga agar mendapatkan sebuah citra positif. Selain itu manfaat dari penelitian ini adalah memberi temuan baru yang tidak ada pada penelitian-penelitian sebelumnya, serta dapat menjadi sumber referensi untuk penelitian selanjutnya dalam ilmu hubungan internasional. Penelitian dibatasi pada era pemerintahan Joko Widodo, yakni tahun 2014-2017, ketika penelitian ini dilakukan 
Menunut Paul Rockower, gastrodiplomacy merupakan upaya diplomasi publik a. meskomunikasikan budaya kuliner suatu negara kepada publik asing dengan cara us e enit menyebar. (Paul Rockower, 2014:14). Gastrodiplomacy sendiri bertujuan untuk a

merujuk ig pada data aimana kita is kualitatif analisis isi ana peneliti am televisi, Hubungan gan berupa formasi dari tronik yang atur, jurnal, elektronik, enelitian ini Belanda era enelitian ini n hubungan masi publik bersaing di hendapatkan temuan baru fadi sumber I. Penelitian a penelitian man- Aan dipromosikan kepada masyarakat asing secara luas. Rockower menilai men zermodiplomacy dapat dikatakan sebagai cara terbaik untuk memenangkan hati = pisiran melalui perut. Rockower juga berpendapat bahwa penggunaan zersafiplamacy secara formal bisa menjadi program resmi pemerintah yang digunakan ama mes genalkan makanan khas negara sebagai tujuan dari diplomasi suatu negara. Rca.wer, 2011). Gastrodiplomacy memungkinkan negara-negara untuk menggunakan muse masional mereka sebagai soft power untuk meningkatkan daya tarik, promosi maves massia, nilai-nilai, dan cita-citanya, (Ichijo \& Ranta, 2016)

Gastrodiplomacy pertama kali digunakan oleh Thailand, sebagai bagian dari =urm publik yang pertama kali dipraktekkan melalui program Global Thailand Thers pada tahun 2002. (Rockower, 2010. The Gastrodiplomacy Cookbook., III ...h huffingtonpost.com/paul-rockower/the-gastrodiplomacy-

mac, $75555 . h$ tml), Program ini berusaha untuk meningkatkan jumlah restoran Tarius de seluruh dunia dengan tujuan mempekerjakan koki-koki Thailand. Sice program ini lalu mulai diikuti oleh negara lain, di antaranya Korea Sclatan,  -a z-tak makanan negara mereka yang lalu mulai 2009 dipromosikan ke dunia ane nel-acurkan proyek Diplomasi Kimchi yang dikenal dengan program Global Lamik xarg berarti Masakan Korea ke Dunia. Tujuan dari diplomasi ini adalah untuk mumanan keunikan dan kualitas kesehatan masakan Korea serta untuk mensarsat jumlah restoran Korea di dunia yang dimulai dengan menggunakan kimchi makan utamanya. (Nelson, D. \& Silva, N. (2016). How South Korea Uses Giner to Connect To The World - And Beyond. http://www.npr.org/ Enimstheal *2016/08/22/489805398/how-south-korea-uses-kimchi-to-connect-tozerris-and-beyond). 
Dengan demikian, dapat diketahui bagaimana respon dan selera masyarakat di suatu tempat (negara) terhadap Kimchi, sebagai ikon yang menimbulkan image bahwa kimchi identik dengan Korea. Lebih lanjut diharap akan menimbulkan minat publik negara lain untuk lebih mengenal Korea.

$\mathrm{Hal}$ ini berbeda dengan Indonesia. Indonesia yang kaya aneka kuliner yang khas, belum memiliki program spesifik mengenai menu makanan yang akan dipromosikan kepada publik internasional sebagai image/brand negara. Hal tersebut disebabkan karena banyaknya ragam kuliner Indonesia yang tersebar dari Sabang sampai Merauke, sehingga Indonesia melakukan gastrodiplomacy lebih kepada pengenalan akan semua jenis kuliner Indonesia, walaupun butuh proses yang lebih memakan waktu ketimbang dengan memperkenalkan hanya satu jenis kuliner. Gastrodiplomacy Indonesia dilakukan dengan upaya lebih kepada pengenalan jenis-jenis masakan Nusantara, baik makanan, minuman, camilan, hingga cara memasak yang ditampilkan kepada publik internasional. Karena salah satu negara yang telah memiliki banyak restoran Indonesia di luar negeri adalah Belanda, maka pemerintah Indonesia memulainya dari Belanda dalam menunjukkan citranya sebagai negara dengan kuliner yang menarik. Menurut Rockower, terdapat beberapa indikator strategi gastrodiplomacy yang digunakan oleh pemerintah untuk memperkenalkan makanan khas negaranya, yakni dengan : Berkomunikasi mengenai budaya kuliner dengan publik asing, menyoroti dan mempromosikan kesadaran dan pemahaman budaya kuliner nasional kepada publik asing berupa state to public relations, yakni hubungan yang dibangun suatu negara dengan publik atau masyarakat negara lain sebagai upaya tertentu yang bertujuan membantu sebuah perusahaan, oganisasi, badan atau institusi agar publik mau bekerja sama dengan baik kepada negara yang bersangkutan. (Rockower, 2012: 8). Theaker \& Yaxley, yang merupakan ahli public relations (Theaker \& Yaxley, 2012: 316), yang mengelompokkan elemen-elemen penting dalam pelaksanaannya yakni: 1) Pemasaran produk; 2) penggunaan Event; 3) Membangun kemitraan dengan Organisasi Internasional di luar negeri; 4) Penggunaan Leader Opinion, 5) membangun hubungan melalui media, maupun ; 6) melalui Pendidikan.

Dengan meminjam 6 indikator yang dibuat Theaker \& Yaxley tersebut, tampak bahwa upaya gastrodiplomacy Indonesia di Belanda sudah melakukan semuanya, baik dilakukan dengan mulai dari pemasaran produk makanan Indonesia di Belanda, adanya 
tasyarakat di mage bahwa minat publik r yang khas, lipromosikan abkan karena ake, sehingga jenis kuliner oang dengan tukan dengan in, minuman, onal. Karena egeri adalah nenunjukkan wer, terdapat rintah untuk si mengenai esadaran dan blic relations, at negara lain nisasi, badan negara yang n ahli public emen penting n Event; 3) Penggunaan 6) melalui sebut, tampak muanya, baik landa, adanya asernez produk - produk makanan Indonesia mudah ditemukan di berbagai toko ace wang tersebar di berbagai kota di Belanda, diantaranya Toko Oriental. Di toko une ne, sal berbagai produk impor dari negara negara Asia, antara lain Jepang, Korea, kierm. Thailand, Malaysia, Singapura dan Indonesia tersebut, berbagai produk anesia modah ditemukan, termasuk tempe (di Belanda lebih dikenal sebagai tempeh). Iit as a si tempe hampir setiap hari tersedia dengan harga 1,4 euro untuk ukuran 400 par Hake 24 Januari 2018. Tempe dapat menjadi terobosan yang baik dalam zeracelomacy Indonesia di Belanda, mengingat bahan utama pebuat tempe, kedelai mame Lidupat, dan sudah ada produsennya di Belanda, sehingga harganya relatif zurpar. Scbuah perusahaan tempe di Belanda, Soya Bean Company bertempat di Crate. Belanda dan pendirinya adalah Robbert van Dapperen. Pada tahun 1979, menear tempenya pindah ke sebuah gudang cii Rotterdam. Dari tahun ke tahun mtraw ini maju dengan sasaran masyarakat Belanda, toko-toko Indonesia di Belanda, anes insosesia yang tinggal di Belanda, hingga diekspor ke seluruh dunia. Tempe yang zenz Ierman sendiri adalah buatan Belanda. (Steggman,G.:2015, Tempe Ala Dibuat di Belanda, Diekspor ke Seluruh Dunia. Diperoleh dari: Iñ $\cdots$ kempasiana.com/gagañawati/tempe-ala-indonesia-dibuat-di-belanda-di aprstakl nuh-dunia_55114b2c813311a941bc6333). Selain tempe, berbagai produk lame- ja mudah ditemui di Belanda, antara lain Indomi, Teh Botol Sosro, Kopi Gres tas bahkan daun pisang, pete, terasi, petis, dsb.

\section{Ceameígiumacy Melalui Berbagai Event di Belanda}

Selain melalui pemasaran produk, gastrodiplomacy Indonesia di Belanda juga ainase thelalui berbagai event. Dalam upaya gastrodiplomacy Indonesia di Belanda, car: nerrykan aktor pemerintah yang berperan penting. Tidak hanya melalui acara -s ascienzearakan oleh KBRI yang berlokasi di Den Haag, tetapi KBRI juga kerap 
berpartisipasi dalam berbagai event kuliner yang diadakan di Belanda. Pemanfaatan berbagai event dalam upaya gastrodiplomacy, dapat menjadi suatu langkah yang memiliki daya tarik Iebih besar dari sekedar promosi restoran.

Beberapa event ataupun festival di Belanda yang menjadi sasaran utama gastrodiplomacy Indonesia antara lain berupa event khusus kuliner, workshop kuliner, event kuliner rutin tahunan, festival kebudayaan, festival musik, hingga event pada tanggal-tanggal penting nasional. Berbagai aktifitas tersebut antara lain tampak pada pada tabel 1 berikut.

Dari tabel I tersebut, tampak bahwa pemerintah Indonesia era Joko Widodo, dalam hal ini terutama dimotori oleh KBRI di Den Haag relatif aktif berpartisipasi dalam event kuliner sebagai bagian dari gastrodiplomacy.

Pada event Taste of Amsterdam, yang merupakan festival kuliner tahunan, dan biasanya diselenggarakan di Amstelpark, Amsterdam, semua pengunjung berkesempatan untuk mencicipi hidangan terbaik dari restoran-restoran kelas menengah dan papan atas di Belanda. Selain itu, Taste of Amsterdam juga menghadirkan workshop, pasar makanan, dan acara musik. ' (Taste of Amsterdam: What is Taste of Amsterdam. (2017). Tersedia dari: http:/en.tastcofamsterdam.com/taste-of-adam-2017/what-is-taste-of. adam.html).

Tabel 1

Gastrodiplomacy Indonesia Melalui Beberapa Event di Belanda

\begin{tabular}{|c|c|c|}
\hline No. & Nama Event & Tanggal \\
\hline 1 & Taste of Amsterdam 2015 & 4 - 7 Juni 2015 \\
\hline 2 & Tong Tong Fair 2016 & 28 Mei - 5 Juni 2016 \\
\hline 3 & Taste of Amsterdam 2016 & 1 - 4 Juni 2016 \\
\hline 4 & Indonesia Week 2016 & 7 - 13 November 2016 \\
\hline 5 & Vakantiebeurs 2017 & $10-15$ Januari 2017 \\
\hline 6 & Tong Tong Fair 2017 & $25 \mathrm{Mei}-5$ Juni 2017 \\
\hline 7 & Taste of Amsterdam 2017 & $2-5$ Juni 2017 \\
\hline 8 & Pasar Raya Indonesia 2017 & $15-17$ September 2017 \\
\hline 9 & Embassy Festival 2017 & 2 September 2017 \\
\hline 10 & Resepsi Diplomatik 2017 & 6 September 2017 \\
\hline
\end{tabular}


manfaatan

kah yang

ran utama op kuliner, svent pada - pada pada

o Widodo, pasi dalam hunan, dan esempatan papan atas $r$ makanan, m. (2017). is-taste-of-

Kehadiran Indonesia dalam Taste of Amsterdam adalah berkat kolaborasi KBRI Zien faug dengan Asosiasi Chef Indonesia di Belanda selama bertahun-tahun. Kini ain memiliki nama baik di event Taste of Amsterdam sebagai negara yang anis digemari oleh masyarakat Belanda. Partisipasi KBRI Den Haag di Taste of anc-2 dimulai sejak tahun 2014. Paviliun Indonesia tidak pernah sepi pengunjung. ב-u tyarik hidangannya yang luar biasa.

Kassa Usaha Ad Interim (KUAI) KBRI Den Haag mengungkapkan, bahwa acsua fartrodiplomacy ini pengunjung juga sekaligus diperkenalkan budaya makan mubaema dari berbagai daerah di Indonesia. Pihak KUAI mengharapkan agar mesura Belanda terutama anak mudanya terus mengenal masakan Indonesia, dan ares mesborong jumlah wisatawan Belanda yang berkunjung ke Indonesia.(KBRI Den the Fr foen Indonesia di Taste of Amsterdam 2015, http://ina indonesia.nl/index.php/allaze :Lssial-budaya/929-paviljoen-indonesia-di-taste-of-amsterdam-2015). Ketika areras mencintai suatu makanan, maka akan timbul rasa ingin tahu untuk mencari asal ant Tses makanan tersebut.

Fartsipasi Indonesia dalam Taste of Amsterdam selalu memberikan tema yang mea stip tahunnya. Pada tahun 2015 Indonesia mengusung tema Wonderful Taste or inemene, pada tahun 2016 dengan tema Indonesia Coffee House, dan pada tahun 2017 are Extic Flavours of Indonesia. Mulai dari camilan, makanan khas daerah, max ver

Scla melalui taste of Amsterdam, Indonesia juga aktif berpartisipasi dalam sisuta (Vakantiebeurs), yakni adalah sebuah ajang pameran tahunan promosi zarnosan tethesar tahunan yang diselenggarakan di Belanda. Vakantiebeurs ane beragam pilihan pariwisata khususnya untuk paket liburan terbesar di Ener ar: teikti oleh peserta dari berbagai negara Eropa, Asia, Amerika dan Afrika. Tameren 2017 misalnya, diikuti Iebih dari 1.083 ekshibitor dan diperkirakan uniturats labilh dari 120.000 orang selama 6 hari penyelenggaraan pameran

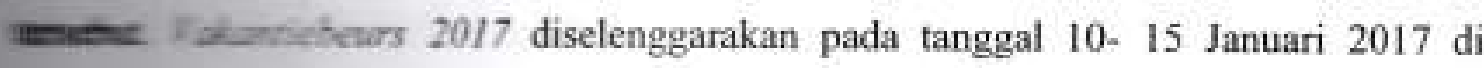
Aure Eativise Convention Centre Hall, Utrecht, Belanda. (KBRI Den Haag; amaimeses pada Vakantiebeurs 2017 di Utrecht.

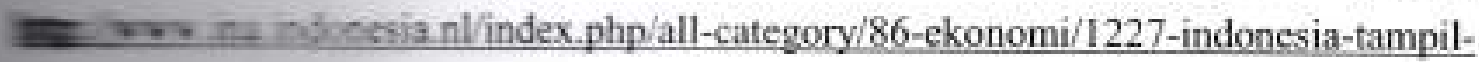
Ine-pertichear-2017-di-utrecht). 
Pada Vakantiebeurs 2017 tersebut, Indonesia melalui gerai yang dinamakan Paviliun Indonesia menyajikan kuliner terbaiknya guna promosi wisata Indonesia. Paviliun Indonesia yang dikoordinasikan oleh Kementerian Pariwisata RI, dengan didukung KBRI di Den Haag, berdiri megah di tengah area Asia pada pameran tersebut. Kuliner yang disajikan adalah minuman tradisional Indonesia yang mengunakan rempahrempah, di antaranya Kunyit Asem Markisa, Markisa Jahe, Kopi Kapulaga, Kopi Pamungkas, Teh Kapulaga Kayu Manis, dan Teh Jahe Lemon yang terbuat dari kayu manis, kapulaga, jahe, kunyit, cengkeh, sereh, asem jawa, gula aren, daun pandan, dan biji pala.

\section{Paviliun Indonesia di Vakantiebeurs, Utrecht, 11-17 Januari 2017}

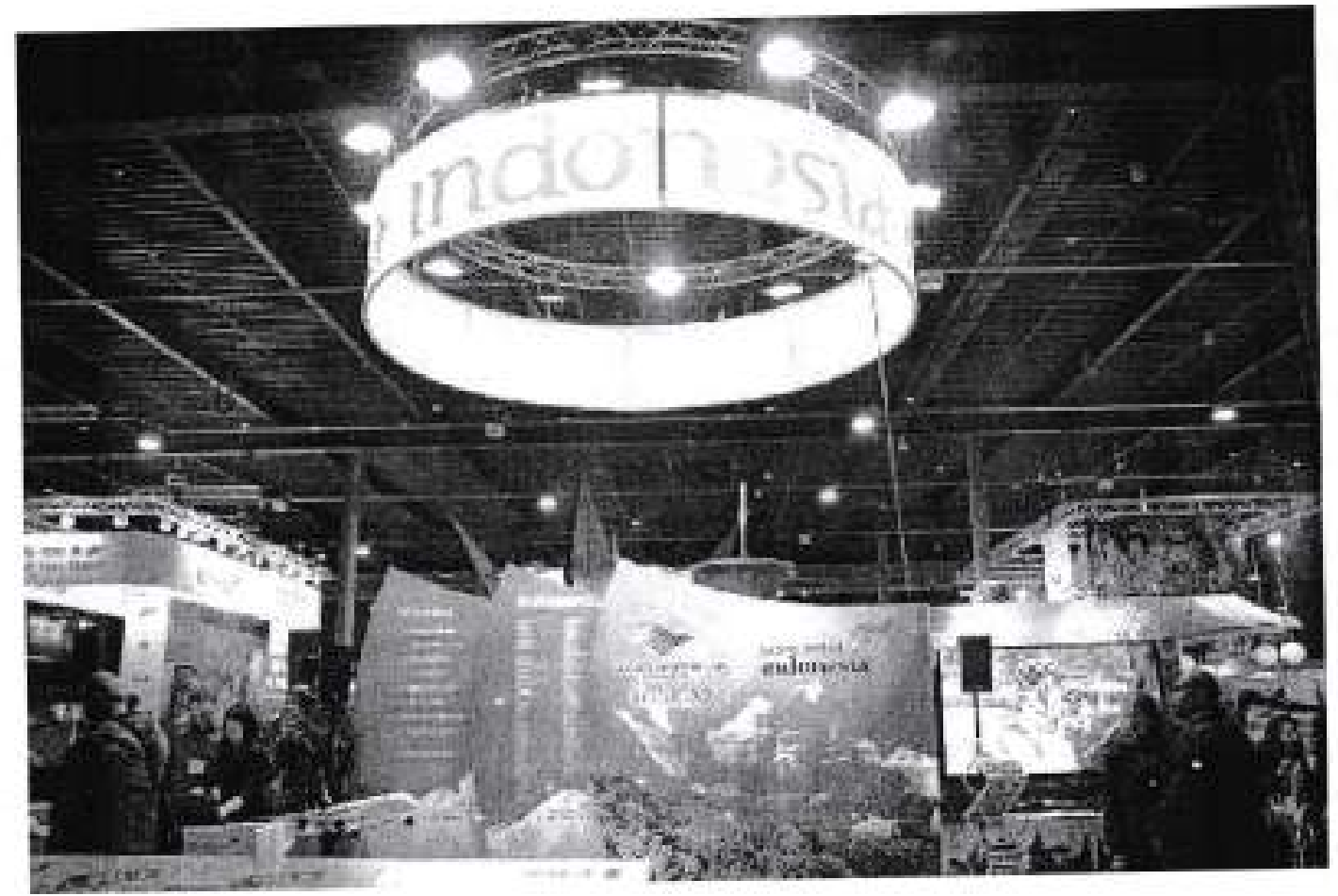

sumber : https://twitter.com/kbridenhaag/status/818909771126505473, diakses 24 Jamuari 2018.

Tong Tong Fair yang merupakan festival Tahunan Eurasia terbesar di dunia yang diselenggarakan di Den Haag, memamerkan berbagai produk budaya, pameran fote. buku-buku, workshop, kuliner dan pertunjukan kesenian dari negara negara Eropa das Asia. Dengan ratusan pertunjukan, Tong Tong Festival menawarkan perpaduan terbaik antara budaya Timur dan Barat dalam sebuah program yang luas yang dilengkapi dengat 
dinamakan a Indonesia. RI, dengan ran tersebut. kan rempahulaga, Kopi tat dari kayu pandan, dan

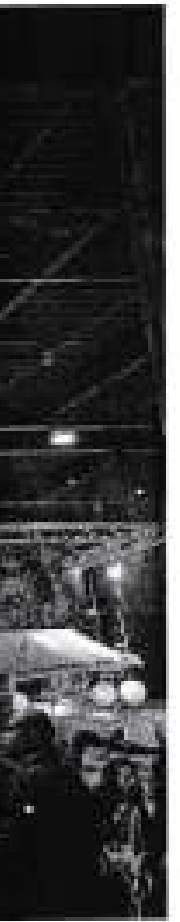

diakses 24

sar di dunia, sameran foto, ra Eropa dan duan terbaik gkapi dengan 


\section{Event Embassy Festival 2017}

Pada 2 September 2017, KBRI juga turut berpartisipasi dalam acara Embassy Festival 2017 di Lange Voorhout, Den Haag, Belanda. Festival rutin yang diselenggarakan Pemerintah Kota Den Haag dan diikuti olch 43 negara yang berasal dari hampir seluruh benua ini diselenggarakan untuk mempromosikan dan memperkenalkan budaya berbagai negara di dunia kepada masyarakat Belanda. (KBRI Den Haag: Kemeriahan Tenda Indonesia pada Embassy Festival 2017. (2017), http//ina.indonesia.nl/index.php/all-category/128-sosial-budaya/1339-kemeriah-antenda-indonesia-pada-embassy-festival-2017. Dengan tujuan mempromosikan cita rasa makanan Indonesia dan memperkenalkannya kepada publik Belanda, pada ajang ini Indonesia turut menjajakan berbagai makanan khas seperti Nasi Kucing, Dadar Gulung, Sate Ayam, Martabak Telur, Lumpia, Mie Bakso, Nasi Goreng, Bakmi Goreng, Pastel, hingga Es Cendol. Indonesia juga turut menampilkan demo memasak secara langsung, yaitu membuat Lak-lak dan Martabak Telur.

\section{Event Resepsi Diplomatik 2017}

Resepsi Diplomatik sebagai rangkaian perayaan Hari Ulang Tahun RI juga kerap diselenggarakan KBRI di Den Haag. Pada Resepsi Diplomatik memperingati hari Ulang Tahun RI ke-72, diselenggarakan di kediaman Duta Besar RI Den Haag, Kerkeboslaan 2. 2243 CM, Wassenaar, pada 6 September 2017. Resepsi Diplomatik 2017 dihadiri oleh lebih dari 800 undangan, para Duta Besar dan kalangan Korps Diplomatik, pejabat dari berbagai institusi pemerintah Belanda, termasuk anggota Parlemen dan Senat Belanda, mitra kerja organisasi internasional, dan para Indonesianis. Pada kesempatan in dimanfaatkan pula untuk mempromosikan minuman buatan Indonesia, yaitu Sababa Wine dari Bali, Bir Bintang, dan Stark Beer. Di tahun 2016, Sababay Wine berhasi meraih medali perak pada kompetisi wine terbesar di dunia, untuk tiga produknya Sementara Stark Beer berhasil memenangkan penghargaan perak Asia Beer Award 201 untuk produk Stark Lychee Ale. Duta Besar Wesaka Puja juga mengapresiasi dukungan dari berbagai pengusaha bidang food and beverage di Belanda yang turu: menyebarluaskan kuliner Indonesia di resepsi, seperti Restoran Bali James, Restorat 
ara Embassy

utin yang berasal dari perkenalkan Den Haag: (2017) iah-an-

an cita rasa ta ajang ini dar Gulung, reng, Pastel, a langsung,

I juga kerap hari Ulang keboslaan 2 , ihadiri oleh pejabat dari at Belanda, mpatan ini tu Sababay ine berhasil produknya. Award 2017 i dukungan yang turut $s$, Restoran

aurnarz, Restoran De Poentjak, Kopi Dua, dan Sayah Liquor. (KBRI Den Haag: Resepsi KBRI Den Haag. (2017). Tersedia dari: http//ina.indonesia.nl/index.phpiall2-politik/1342-resepsi-diplomatik-kbri-den-haag-6-september-2017).

\section{Serrefiplomacy Melalui Organisasi Pemerintah \& Non Pemerintah}

Dorongan Perhimpunan Ahli Gizi dan Pangan (Pergizi Pangan) Indonesia dan Fram Tempe Indonesia kepada pemerintah agar mengajukan Tempe Sebagai Warisan Tat Benta kepada UNESCO schingga Indonesia mempunyai hak paten Tempe, a mase sarisan budaya kuliner Indonesia. Gastrodiplomacy, melalui pengajuan paten $\mathrm{man}$ ANESCO tersebut, diharap orang dapat mengetahui identitas suatu negara melalui main yang mereka makan, dan sebaliknya, sehingga melalui UNESCO, negara dapat ancen tas identitas negaranya dari makanannya, dalam hal ini tempe bagi Indonesia. Selitin itu terdapat NGO Indonesia Safu Foundation yang terdiri dari orang orang ans sesal dari Indonesia dan memiliki minat terhadap makanan Indonesia, dan amere tesur adalah para chef Indonesia yang bekerja di Bclanda. (Indonesia Satu: abar . - 2017, http://www indonesiasatu.nl/about-us ). Indonesia Satu berada dibawah $\underline{E}=\mathrm{E}$ afsilitasi olch KBRI di Belanda. Dengan latar belakang dan kemampuan ans ethete, para chef saling melengkapi satu sama lain. Indonesia Satu beberapa kali acempratan event di Belanda, diantaranya Indonesische Kookwedstrijd Inaverus (Cokting Competition) yang berlangsung di Den Haag pada 2014, Diaspora ansur Fine Dining with Dino Patti Jalal (Desember 2014). Sedangkan pada tahun $2: \leq$ artars lain mengadakan Projects Ethnic Foods Europe, Wonderful Taste of anase Dyplomatic Reception, Pesta Rakyat di Wassenaar Fashion Show:

anus 4 - C Whare and Performance dan Gastronomie Jaarbeurs Utrecht. Indonesia in: the 2h sects 2017, http:/www.indonesiasatu.nl/projects).

Sicheres evont kuliner yang diselenggarakan pada tahun 2016 antara lain Foram, Indonesian Diaspora Network The 2016. Sedangkan pada ב 21- artaranya Horecava RAl Amsterdam 2017, Indonesia Satu's Culinary pada Maret 2017, dan Soldaat van Oranje "The Musical" Jo0th 
Anniversary of Erik Hazelhoff pada April 2017.(Indonesia Satu, ibid) Gastrodiplomacy Melahi Opinion Leader

Meminjam pemahaman dalam perspektif sosiologi komunikasi, opinion leader digambarkan sebagai tokoh yang memiliki pengaruh, dan secara sosial ekonomi berbeda dengan masyarakat lain. Beberapa tokoh yang berperan penting dalam gastrodiplomacy Indonesia antara lain Perdana Menteri Belanda Mark Rutte, Menteri Luar Negeri Retno Marsudi, dan secara tidak langsung, Presiden Amerika Serikat ke-44 Barrack Obama.

PM Belanda Mark Rutte menyampaikan bahwa dirinya tidak bisa tanpa masakan Indonesia. Disampaikan bahwa bukanlah hal yang aneh ketika PM Rutte menyukai masakan Indonesia, mengingat kedua orang tuanya pernah tinggal selama bertahun-tahun di Indonesia yang dahulu masih Hindia Belanda.( Detik News. (2012). Detik: PM Belanda Penggemar Masakan Indonesia!. Diperoleh dari: (http://news.detik.com/berita/2014143/pm-belanda-penggemar-masakan-

indonesia\#main). Dengan pernyataan PM Rutte tersebut, maka hal itu menjadi sebuah opinion leader yang dapat mempengaruhi publik Belanda dan mendatangi restoranrestoran berkonotasi Indonesia di Belanda.

Lalu ada Menteri Luar Negeri Retno Marsudi pada kesempatan di Taste of Amsterdam 2016, menyampaikan bahwa diplomasi kuliner Indonesia perlu terus digalakkan ke seluruh dunia, sebab dampak berlipat gandanya berbanding lurus dengan kesejahteraan bangsa. Menlu Retno memandang bahwa dengan hadirnya gastrodiplomacy Indonesia di seluruh dunia, akan menjadikan keuntungan bagi Indonesia dalam hal kesejahteraan masyarakat Indonesia di luar negeri maupun pariwisata dalam negeri.( Detik News. (2016). Detik: Menlu: Diplomasi Kuliner Perlu Terus Digalakkan ke Seluruh Dunia. Diperoleh dari: (http://news.detik_com/berita/d-3226862/menludiplomasi-kuliner-perlu-terus-digalakkan-ke-seluruh-dunia). Secara tidak langsung Menlu Retno ingin mengajak para pengusaha dalam bidang kuliner Indonesia di Belands untuk terus berkarya dalam mempromosikan kuliner Indonesia.

Presiden Amerika Serikat Barrack Obama yang pada masa kecilnya perna selama 4 tahun tinggal di Jakarta, di hadapan 7.500 undangan, menyatakan sate dan baks sebagai makanan kesukaannya. Obama juga mempraktekkan bagaimana ketika diriny 
pinion leader nomi berbeda trodiplomacy Negeri Retno ck Obama.

anpa masakan tte menyukai ertahun-tahun

). Detik: PM eh dari enjadi sebuah ungi restoran.

n di Taste of perlu terus lurus dengan an hadimya agi Indonesis iwisata dalam

Digalakkan ke 26862/menluak langsung. sia di Belanda cilnya pernah sate dan bakso ketika dirinys 


\section{Gastrodiplomacy Melalui PPI Belanda}

Perhimpunan Pelajar Indonesia (PPI) di Belanda, merupakan salah satu organisasi Perhimpunan Pelajar Indonesia tertua di dunia. PPI Belanda dibentuk pada tahun 1922. dan terbagi terbagi dalam setiap PPI Kota. PPI Kota merupakan PPI Belanda yang dipisahkan dan diorganisir menurut lokasi kota-kota di Belanda tempat para pelajar Indonesia menjalani kehidupan pendidikan.( PPI Belanda: Tentang PPI Belanda (2017).Tersedia di: http://ppibelanda_org/tentang-kami/)

Kedutaan Besar Republik Indonesia di Den Haag membantu memfasilitasi setiap kegiatan dari PPI Belanda yang berhubungan untuk mempromosikan kebudayaan Indonesia di Belanda. KBRI dapat dikatakan berperan sebagai orang tua bagi PPI Belanda. Berikut adalah beberapa PPI Kota yang telah mempromosikan kuliner Indonesia di Belanda dalam event ataupun workshop, diantaranya PPI Groningen,

PPI Groningen merupakan salah satu PPI terbesar di Belanda yang terletak of kota Groningen, di ujung utara Belanda. PPI Groningen berperan penting dalam: gastrodiplomacy Indonesia di Belanda. PPI Groningen termasuk pelopor dan penyelenggara event tahunan Indonesian Dinner, dan lalu dikembangkan menjad Indonesian Day, sejak tahun 2012, merupakan yang terbesar dibanding PPI kota lainnya Beberapa event bertajuk budaya dan kuliner yang telah dilaksanakan oleh PPI Groninge yang diadakan rutin setiap tahun, antara lain Indonesian Day and Dinner, Internationa Cultural Exchange, Indonesian Day and Dinner, dan Groenscup, yakni pertandinga berbagai cabang olahraga antar kota PPI di Belanda. Pada acara tersebut, selalu diadaka bazaar berbagai kuliner Indonesia oleh para mahasiswa ataupun orang orang Indonesi yang tinggal di Groningen, dan terbuka untuk umum, termasuk warga Belanda.

Pada acara Indonesian Day, PPI Groningen menjual tiket, kisaran 10 euro untu dinner berbagai kuliner Indonesia yang disajikan secara piring terbang. Pada acar tersebut disajikan berbagai pentas seni oleh mahasiswa atau pelajar Indonesia yan sedang studi di Groningen. Pada rangkaian acara tersebut, kadang juga ada dem memasak masakan Indonesia, pameran batik, pameran foto keindahan Indonesia, yat semuanya dilakukan olch PPI Groningen dengan didukung oleh KBRI Den Haag. Adap 
$=$ ara Inobesian Day and Dinner sangat variatif, diantaranya Indonesia the

tu organisasi tahun 1922 . elanda yang para pelajar PI Belanda. silitasi setiap kebudayaan tua bagi PPI ner Indonesia ng terletak di enting dalam pelopor dan kan menjadi kota lainnya. PI Groningen Internationa: pertandingan elalu diadakan ang Indonesis anda.

10 euro untut g. Pada acar: adonesia yang uga ada deme donesia, yang Haag. Adapur
Leshasur di Dapur Treslinghuis Pada Indonesian Day 2012, PPI Groningen

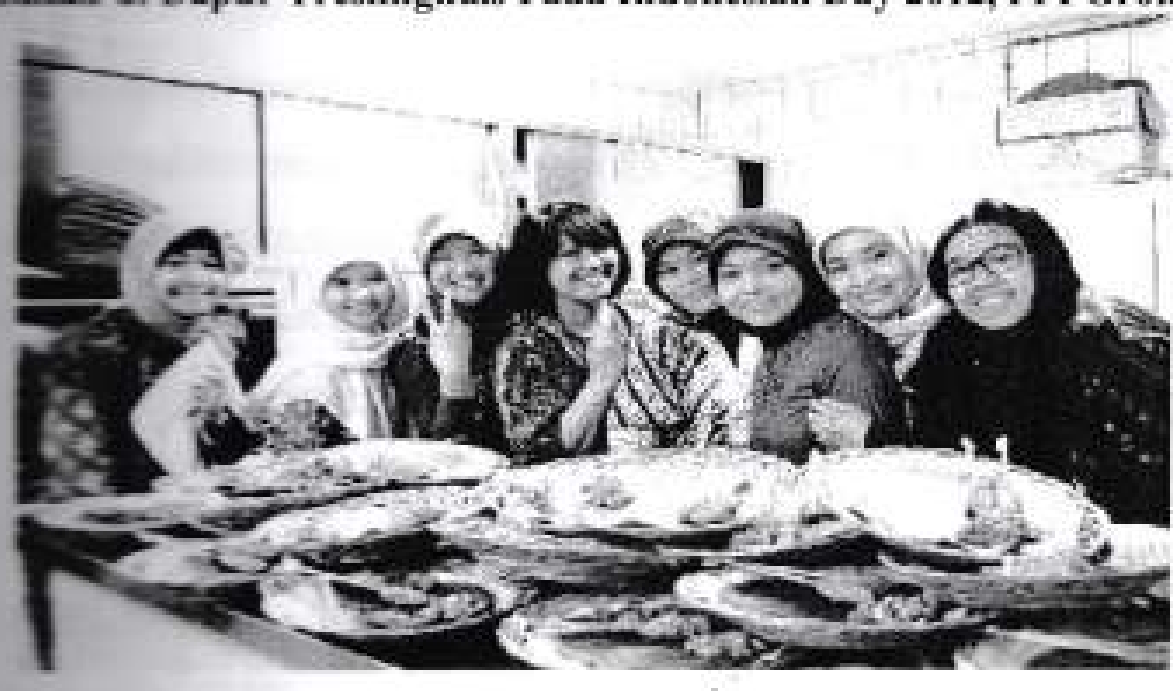

Fan $=y$ : Neil Andika, dokumentasi PPI Groningen.

\section{Gambar 2:}

Amatar a Acara Indonesian Day 2014 Lengkap Dengan Baju Daerah

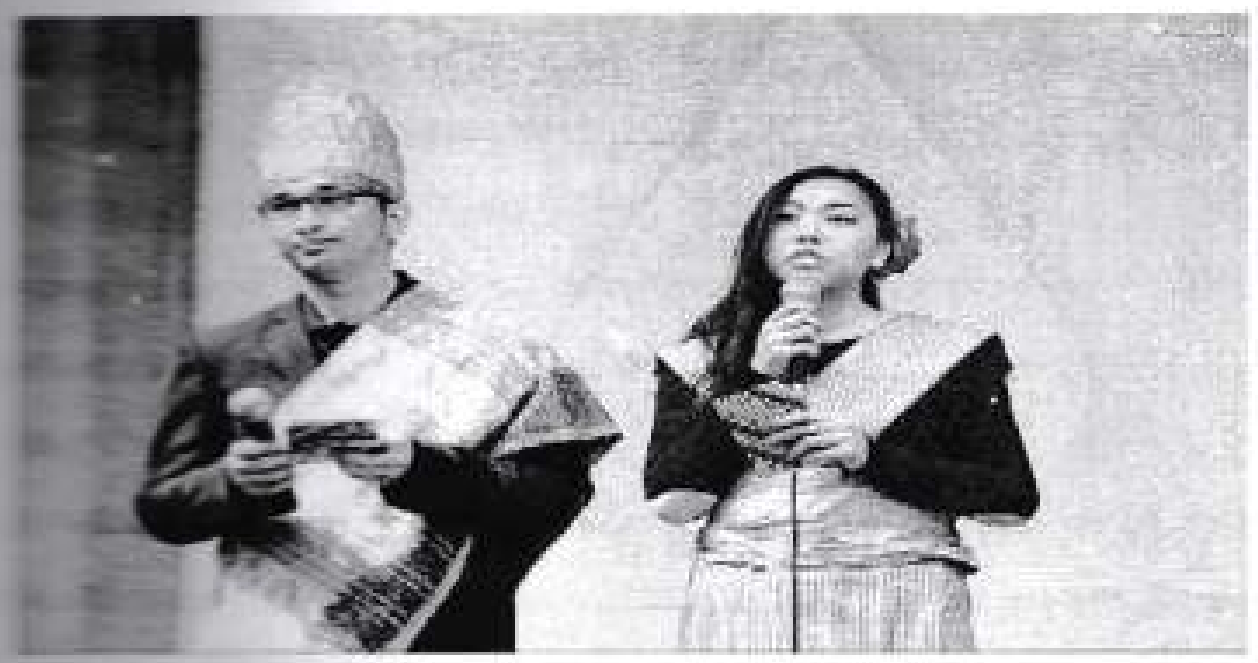

Fas by Surahyo Sumarsono, dokumentasi pribadi

\section{Gambar 1}


Duta Besar Indonesia untuk Kerajaan Belanda Wesaka Puja hadir pada IDD dan memberikan apresiasi atas kegiatan yang mempromosikan kuliner Indonesia.

Kemudian ada International Cultural Exchange (ICE) yang merupakan kegiatan yang diadakan oleh Perhimpunan Pelajar Indonesia (PPI) di Groningen dan telah berlangsung sejak tahun 2012. Diselenggarakannya International Cultural Exchange oleh PPI Groningen bertujuan untuk memperkenalkan negara dan budaya dari negara-negara dari mahasiswa dari mana organisasi berasal. Selain PPI Groningen, PPI Eindhoven juga menyelenggarakan Festival Kuliner pada tahun 2016 dengan tajuk Made in Indonesia 2016. Pihak KBRI Den Haag yang menghadiri acara ini mengungkapkan pentingnya promosi budaya Indonesia. Pihak KBRI Den Haag juga mengatakan bahwa terdapat sekitar $10 \%$ populasi masyarakat Belanda yang merupakan agen-agen diaspora Indonesia dalam promosi budaya dan parawisata Indonesia di Belanda.( PPI Belanda: Semarak Made in Indonesia. (2016).Tersedia dari: httpi/ppibelanda.org/semarak-madeindonesia/)

Bertepatan dengan Hari Pahlawan pada tanggal 10 November 2016, PPI Wageningen mengadakan acara berjudul Temp(e)tation yang diselenggarakan di gedung Forum, Universitas Wageningen. Acara Temp(e)tation mengundang tiga pembicara yaitu Wida Winarno, penggiat Gerakan Tempe Indonesia, Dr. MJ Rob Nout, ahli di bidang Mikrobiologi Pangan, dan Herditya Oktania, pemenang Ecotrophelia 2015. (PPI Belanda: Temp(e)tation PPI Wageningen. (2016). Tersedia dari: http:/ppibelanda.org/tempetation-ppi-wageningen-2016/2. Acara ini bertajuk Discover The Secret of Temp(e)tation. Acara ini merupakan sebuah workshop yang wajib untuk mengenalkan sejarah, manfaat, dan kelebihan tempe kepada publik Belanda.

Pada tahun 2016 lalu, PPI Den Haag mengadakan suatu event untuk mempromosikan kopi asli Indonesia kepada masyarakat Belanda. Acara tersebut berjudul Indonesian Coffee Festival: Indulge the Authenticity of Indonesian Coffee yang berlangsung pada tanggal 17 hingga 18 Juni 2016. Indonesian Coffee Festiva. mempersembahkan pameran kopi, diskusi kopi, acara khusus oleh barista profesional dan talkshow interaktif. (PPI Belanda: Indonesian Coffee Festival: Indulge the Authenticity of Indonesian Coffee. Tersedia dari: httpil/ppibelanda,org/indonesian-coffee-festival-indulge 
da IDD dan a.

akan kegiatan en dan telah xchange oleh tegara-negara ndhoven juga in Indonesia n pentingnya hwa terdapat ora Indonesia da: Semarak marak-madean di gedung nbicara yaith hli di bidang PPI Belanda dari uk Discover wajib untub event untuk but berjudul Coffee yang Fee Festival profesional, uthenticity of tival-indulge: 
satu jenis makanan saja. Hal ini bisa diapahami mengingat Indonesia yang terdiri dar berbagai suku dan mempunyai aneka kuliner yang menarik untuk diperkenalkan kepad dunia. Namun demikian, tempe sebagai salah satu makanan sehari hari yang tersebar c hampir seluruh kota di Indonesia dapat menjadi salah satu ikon gastrodiplomac Indonesia.

Gastrodiplomacy Indonesia di Belanda relatif aktif dilakukan, bahkan sebelur era pemerintahan Joko Widodo. Gastrodiplomacy Indonesia di Belanda menjadi menari karena berperan aktifnya baik lembaga pemerintah, dalam hal ini dimotori KBRI Belanda yang berlokasi di Den Haag, maupun organisasi non pemerintah, seperti pa pelajar dan mahasiswa Indonesia yang tergabung di PPI masing masing kota di Belanda

Mudahnya mendapatkan berbagai bahan dasar masakan Indonesia, seperti temp dan berbagai bumbu, di berbagai kota di Belanda semakin mendukung gastrodiploma Indonesia di Belanda, serta dapat mengurangi rasa rindu siapapun terhdap citaras masakan Indonesia. Aktifnya peran aktor pemerintah dan non pemerintah akan semak mendukung pesatnya upaya gastrodiplomacy Indonesia di Belanda.

\section{Daftar Pustaka}

Bakry, Umar Suryadi , (2016), Metode Penelitian Hubungan Internasional, Yogyakart Pustaka Pelajar

Ichijo, A., \& Ranta, R. (2016). Food, National Identity and Nationalism: From Everyda to Global Politics. New York, NY: Macmillan Publishers Limited.

Cambridge Dictionaries: Culinary in British English. Tersedia dar http://dictionary.cambridge org/dictionary/english/culinary\#translations

Rockower, Paul. (March, 2011), Projecting Taiwan : Taiwan's Public Diploma Outreach 47.1. Institute of International Relations, National Chengchi University Taipei, Taiwan.

Your Pick: World's 50 Best Food, http://edition.cnn.com/travel/article/world-best: foods-readers-choice/index.html, diakses 16 November 2017.

Theaker, Alison. Yaxley, Heather. (2012). The Public Relations Strategic Toolkit: Essential Guide to Successful Public Relations Practice. Canada: Routledge.

Bell, David, \& Valentine, G. (1997) Consuming Geographies: We Are Where We Ee New York: Routledge. 
terdiri dari

Ikan kepada tersebar di odiplomacy tan sebelum adi menarik ri KBRI di seperti para di Belanda. eperti tempe odiplomacy lap citarasa tan semakin Yogyakarta: $m$ Everyday dia dari: ns

Diplomac University

world-best-

Toolkit: As atledge.

ere We Eat

rine. (1998). From Theory to Practice. Experiencing the Nation in Everyday Lfe Journal of Material Culture 3.2:188.

Sumt - Thacple-Sokol. (2013). "Culinary Diplomacy : Breaking Bread to Win Hearts and Minds.". The Hague Journal of Diplomacy, vol. 8 lssue 2. USA: Martius = Thoff Publishers.

arass = Paul. (2012). Recipes for Gastrodiplomacy. Place Branding and Public Insm: 2012. http://publicdiplomacymagazine.com/wp-content/uploads/2013/07/ II: $=-10 P-1$-copy.pdf.

Girm. Aegran (2011). South Korean Cultural Diplomacy and Efforts to Promote the an in limage in The United State and Around The World. Johns Hopkins School at Atranced International Studies. Tersedia dari; Intw s.s. academia.edu/6609624/South_Korean_cultural_diplomacy_and_brokering Btirn artside Asia

Tinas WA. (2013). South Korea's Gastrodiplomacy. Journal of Intemational sene US, https:/thediplomatistdotcom.files.wordpress.com/2013/01/jis-spring2B-aine sutrodiplomacy.pdf

Alit fins Sit. (2006). Food and Nationalism-Kimchi and Korean National Identity. The Kurnas loursal of International Relations 46.5: 207-29.

aumsere ?al (2014, Winter Edition). Public Diplomacy Magazine

Shrres (2011). World's 50 Best Foods. Diperoleh dari:

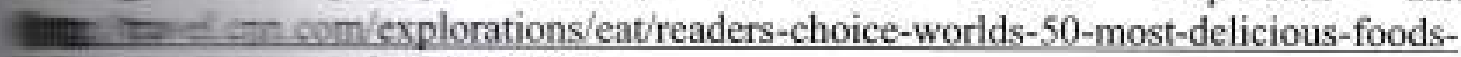
글. tiskes pada 6 Juni 2017

Tharais= (C)17). Tempe: 'Makanan Ajaib' yang (Masih) Dianggap Murahan di anas Dupercleh dari: (http://www.bbc.com/indonesia/indonesia-38529395), diakses

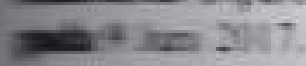

ante- 2015). Tempe Ala Indonesia Dibuat di Belanda, Diekspor ke Seluruh

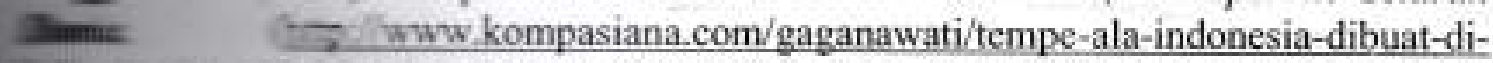

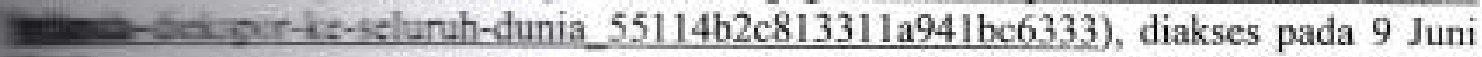
IIIr

and 2010). The Gastrodiplomacy Cookbook. Diperoleh dari:

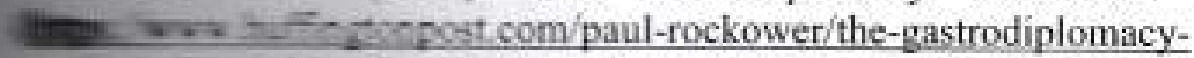
anat. . assf te- diakses pada 30 Oktober 2017.

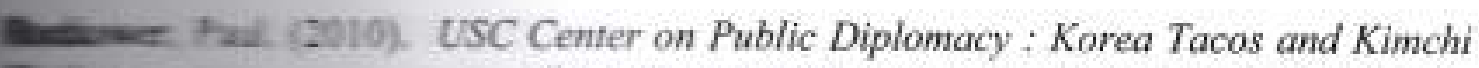
(http:/uscpublicdiplomacy.org/blog/korean_tacos and

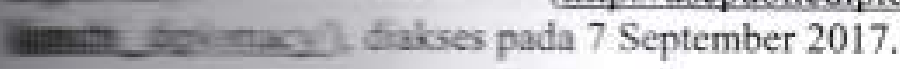


Nelson, D. \& Silva, N. (2016). How South Korea Uses Kimchi To Connect To The World - And Beyond. Diperoleh dari: (http://www.npr.org/sections/thesalt/ 2016/08/22/489805398/how-south-korea-uses-kimchi-to-connect-to-the-world-andbeyond), (diakses pada 7 Semptember 2017)

Steggman,G. (2015). Tempe Ala Indonesia Dibuat di Belanda, Diekspor ke Selurth Dunia. Diperoleh dari: (http:/www.kompasiana com/gaganawati/tempe-ala-indonesiadibuat-di-belanda-diekspor-ke-seluruh-dunia 55114b2c813311a941bc6333), (diakses pada 9 Juni 2017)

Detik News. (2012). Detik: PM Belanda Penggemar Masakan Indonesia!. Diperoleh dari: (http://news.detik.com/berita/2014143/pm-belanda-penggemar-masakanindonesiatmain), (diakses pada 7 Agustus 2017)

Detik News. (2016), Detik: Menlu: Diplomasi Kuliner Perlu Terus Digalakkan ke Seluruh Dunia. Diperoleh dari: (http:/news,detik.com/berita/d-3226862/menludiplomasi-kuliner-perlu-terus-digalakkan-ke-seluruh-dunia), (diakses pada 9 Agustus 2017)

Taylor, G.S. (2017). Obama 'Pulang Kampung' ke Indonesia, Ini Makanan Favoritnya. Diperoleh dari: (https://www.cnnindonesia.com/gaya-hidup/ 2017062 3095811-262. 223740/obama-pulang-kampung-ke-indonesia-ini-makanan-favoritnya/), (diakses pada 30 November 2017)

Cambridge Dictionaries: Culinary in British English. Tersedia dari http://dictionary.cambridge.org/dictionary/english/culinary\#̈translations

UNESCO - ICH. (2013). Washoku, traditional dietary cultures of the Japanese, notably for the celebration of New Year. Tersedia dari: https:/ich.unesco.org/ en/RL/washokutraditional-dietary-cultures-of-the-japanese-notably-for-the-celebration-of-new-year$\underline{00869}$

National Geographic: Sejarah Kopi Luwak, Kopi Termahal di Dunia. (2016). Tersedia dari: http://nationalgeographic.co.id/berita/2016/02/sejarah-kopi-luwak-kopi-termahaldi-dunia

Kementrian Luar Negeri: Indonesia Jadi Portrait Country pada The 28 th Annual Specialn Coffee Association of America. (2016). Tersedia dari https:/www.kemlu.go.id/id/berita/Pages/Annual-Specialty-Coffee-Association-ofAmerica-SCAA.aspx

Taste of Amsterdam: What is Taste of Amsterdam, (2017). Tersedia dari http://en.tasteofamsterdam.com/taste-of-adam-2017/what-is-taste-of-adam.html

KBRI Den Haag: Paviljoen Indonesia di Taste of Amsterdam 2015. (2015). Tersedia dari http://ina.indonesia.nl/index.php/all-category/128-sosial-budaya/ 929-paviljoenindonesia-di-taste-of-amsterdam-2015 
o The Worle tions/thesalt rdd-and-

- ke Seluruh a-indonesia(diakses

1. Diperoleh ar-masakan-

galakkan ke $5862 /$ menlu9 Agustus 95811-262iakses pada

edia

dari:

ese, notably

L/washokuw-year-

5). Tersedia oi-termahal-

al Specialty dari: no-of-

sedia dari $\mathrm{ml}$

rsedia dari -paviljoen-

an. vet Hage Indonesia Tampil pada Vakantiebeurs 2017 di Utrecht. (2017). Tersedia II = sww.ina.indonesia.nl/index.php/all-category/86-ekonomi/ 1227 -indonesia-

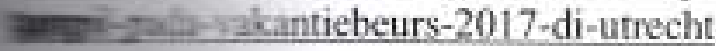

Tnest - Fair Achtergrond. (2009). Tersedia dari: http//tongtongfair.nl/ achtergrond/ E- Te Hag Pemukulan Kentongan Tandai Pembukaan TTF ke-58. (2016). Tersedia I= ta indonesia.nl/index.php/all-category/128-sosial-budaya/ 1087 -pemukulansmin = indai-pembukaan-tong-tong-fair-ke-58

EE De Haag: Indonesia Week 2016. (2016). Tersedia dari: $=$ s.w. kemlu.go.id/id/berita/berita-perwakilan/Pages/Indonesia-Week-2016.aspx

Ele Zen Harg Kemeriahan Tenda Indonesia pada Embassy Festival 2017. (2017). Tez http:/ina.indonesia.nl/index.php/all-category/128-sosial-budaya/1339.

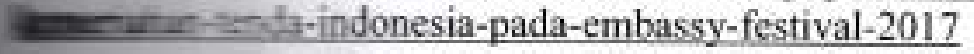

EIE He Hag: Resepsi Diplomatik KBRI Den Haag. (2017). Tersedia dari: In mónesia nt index.php/all-category/102-politik/1342-resepsi-diplomatik-kbrianturstostember-2017

anas= San. About Us. (2017). Tersedia dari : http:/www. indonesiasatu. nl/about-us aheunres Sart, Our Projects. (2017). Tersedia dari: http://www.indonesiasatu. nl/projects min seme Tentang PPI Belanda. (2017).Tersedia di: http://ppibelanda.org/ tentang. am 3esolar Semarak Made in Indonesia. (2016). Tersedia dari: ItE= mocinchuorg/semarak-made-indonesia/

In Sumb Temp(e)tation PPI Wageningen. (2016). Tersedia dari: IIrenfe arglempetation-ppi-wageningen-2016/

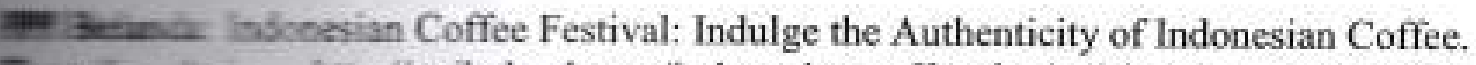
tan: Ha/lopibelanda-org/indonesian-coffee-festival-indulge-authenticity-

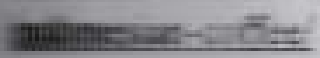

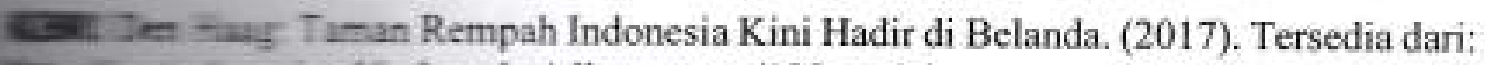
z = maresiz-lindex php/all-category/128-sosial1317-taman-rempah-

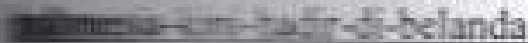
hitps://twitter.com/kbridenhaag/

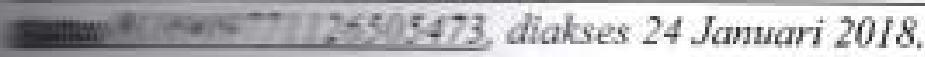

